\title{
Aus der Ratsstube
}

\section{Werner Bauer}

Dr. med., Präsident des Schweizerischen Instituts für ärztliche Weiter- und Fortbildung SIWF

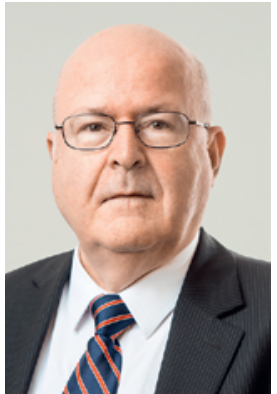

Beim Blättern in einer Bündner Zeitung ist mir die Rubrik «Aus der Ratsstube» aufgefallen. Sie beinhaltet die Beschlüsse des Gemeinderates. Mich hat die Wortwahl angesprochen, weil sie den Lesern den Eindruck gibt, sie könnten selber einen Blick in die Ratsstube tun - ich stelle mir ein ehrwürdiges Sitzungszimmer mit Arventäfer und Butzenscheiben vor.

Auch die Geschäftsleitung des Schweizerischen Instituts für ärztliche Weiter- und Fortbildung hält Sitzungen $a b$, in einem nüchternen Raum in Bern und nicht in einer Arvenstube. Viele Leser haben wohl keine Vorstellung von den Geschäften, die beim SIWF auf der Traktandenliste stehen können. Ich nutze die Gelegenheit des «Zu guter Letzt» für einen Blick in die «SIWFRatsstube» - selbstverständlich unter Beachtung aller Regeln der Vertraulichkeit.

Wie bei Sitzungen üblich geht es los mit der Genehmigung des Protokolls und mit den Mitteilungen des Präsidenten. Die Erfahrung zeigt, dass sich die Mitglieder protokollverfassender Gremien in zwei Gruppen einteilen lassen: eine kleinere, die sich bei der Genehmigung möglichst regelmässig mit einem Präzisierungsbedarf oder dem Hinweis auf einen Druckfehler zu Wort meldet, und eine grössere, die das Protokoll bei der Anreise zur Sitzung überflogen oder im Vertrauen auf dessen Korrektheit gar nicht gelesen hat und grosszügig-heiter Zustimmung signalisiert. Die SIWF-Geschäftsleitung allerdings besteht durchwegs aus aufmerksamen Protokolllesern, einer sonst nur schwer auffindbaren dritten Gruppe.

Das Traktandum der Mitteilungen von Präsident und Geschäftsführer ist für den Sitzungsverlauf gar nicht immer so harmlos, wie es tönt, hat es doch die Tendenz, auszuufern oder unerwartete Kommentare auszulösen. Wenn nach der ersten Stunde der Mitteilungsfluss immer noch anhält, ist die Sitzungsleitung schon ernsthaft gefordert.

Das nächste Traktandum ist das Projekt «Neuentwicklung des e-Logbuchs». Es geht dabei um ein Kerngeschäft des SIWF, denn im Logbuch müssen alle erfüllten Anforderungen und Weiterbildungsschritte dokumentiert werden, welche Voraussetzung für die Erteilung eines Facharzttitels sind. Zurzeit muss das aktuelle e-Logbuch, das den Anforderungen nicht mehr genügt und auch nicht weiterentwickelt werden kann, durch eine neu erarbeitete Version ersetzt werden. Dieses
Traktandum löst ein gemischtes Gefühl zwischen $\mathrm{Zu}$ versicht und bangem Herzklopfen aus, trägt die Geschäftsleitung doch die Verantwortung, ist aber für das Wahrnehmen dieser Verantwortung auf die IT-Experten angewiesen. Für medizinische Themen und solche der Weiter- und Fortbildung fühlen wir uns einigermassen kompetent. Wenn es um das Leiten und Begleiten eines IT-Projektes geht, braucht es vor allem Vertrauen in die Fachleute und eine ordentliche Prise Hoffnung.

Ein nächstes Traktandum führt zurück in vertraute Gefilde, zur Bearbeitung und Genehmigung der Revision von Weiterbildungsprogrammen. Es ist bemerkenswert, wie häufig eine der 45 Gesellschaften, die einen Facharzttitel verwalten, die Absicht bekundet, ihr Curriculum zu aktualisieren. Da geht es zum Beispiel um das Einfügen oder Streichen von Lernzielen, um die Erhöhung oder Senkung der Anzahl geforderter Operationen oder um eine Präzisierung der Kriterien für die Anerkennung von Weiterbildungsstätten. Nicht immer ist ein solcher Entscheid unproblematisch, dann zum Beispiel nicht, wenn er administrativ aufwendige Übergangsbestimmungen notwendig macht oder wenn er von einer anderen Fachgesellschaft als unfreundlich betrachtet wird, weil sie fürchtet, dass der «Gartenzaun» um ihre eigenen Lernziele herum eingerissen wird. Da ist Vermittlung gefragt!

Nach der Pause mit Frischluft und Espresso folgt eine Reihe weiterer Traktanden: Nach dem obligatorisch-besorgten Blick auf die Finanzen geht es um die Vorbereitung von Tagungen, die Entwicklung eines Projektes «teach the teachers» zur didaktischen Unterstützung der Weiterbildenden, die Anerkennung der Zertifikate europäischer Organisationen oder deren Einbau in unser Titelsystem und um die heikle Frage, ob und in welcher Form wir Adressen oder andere Daten an Partnerorganisationen herausgeben können oder überhaupt dürfen. Einzelne Traktanden lassen Aufbruchsstimmung aufkommen, andere lösen Stossseufzer aus.

Geseufzt wird zum Beispiel, wenn zu erkennen ist, dass die Weiterbildung als Mäntelchen für Interessenpolitik genutzt werden soll oder wenn eine Behörde ihrer Phantasie schwer nachvollziehbare bürokratisch-regulatorische Ideen entspringen lässt.

Zum Schluss vielleicht noch ein Varium, dann gehen die Lichter in der Ratsstube aus. 